\title{
Борьба ЮНИСЕФ \\ с наркоманией среди детей
}

Мусина Н.M. ${ }^{*}$

В преамбуле к Единой Конвенции о наркотических средствах 1961 года говорится: «Наркомания является серьезным злом для отдельных лиц и чревата социальной и экономической опасностью для человечества» ${ }^{1}$. Употребление наркотических средств и психотропных веществ наносит значительный ущерб как личности, так и государству. Ощутимая часть ресурсов здравоохранения уходит на лечение болезней, связанных с наркоманией. В социальной сфере огромные средства выделяются на решение социальных и экономических последствий наркомании.

Особой проблемой является распространение наркомании среди детей, приобщение их к наркотическим средствам и психотропным веществам, вовлечение в наркобизнес, где все больше используют детей, не достигших уголовно наказуемого возраста. Все это делается с целью получения баснословных прибылей без учета интересов беззащитных и легко уязвимых детей.

По экспертным оценкам, размер ежегодного незаконного оборота наркотиков достигает 2-6 млрд. долларов США. Часть этих средств вливается в легальный сектор экономики, существенно деформируя ее, нарушая естественные процессы товарооборота и ценообразования. Широкомасштабное инвестирование таких средств в законный бизнес в состоянии обеспечить преступникам новые рычаги влияния на экономические процессы, существенно расширить их возможности для наращивания преступной активности. Кроме того, основы социально-политической системы страны подрываются коррупцией государственных чиновников, осуществляемой на наркодоходы.

В 90-х годах XX столетия наркобизнес получил развитие даже в тех странах, где незаконный оборот наркотиков и злоупотребление ими ранее вообще не отмечались, при этом резко возросла детская нар-

\footnotetext{
* Мусина Наиля Минсабировна - соискатель кафедры международного права МГИМО (У) МИД России.

${ }^{1}$ См.: Международное право и борьба с преступностью: Сб. документов / Составители: А.В. Змеевский, Ю.М. Колосов, Н.В. Прокофьев. М.: Международные отношения, 2004. C. 276.
} 
комания. Эксперты ООН связывают причины развития транснациональных преступных организаций, в том числе и тех, чьей основной деятельностью является наркобизнес, с появлением соответствующих возможностей на глобальном уровне, что обусловлено долгосрочными тенденциями развития в мировой политике и экономике. В результате увеличения взаимозависимости государств, упрощения международных связей, повышения степени прозрачности национальных границ и формирования глобальных финансовых сетей появились мировые рынки сбыта как законной, так и незаконной продукции ${ }^{2}$.

Наркотические вещества начали употребляться людьми как в медицинских целях, так и в качестве стимулирующего средства еще в древности. Опасность употребления наркотиков была открыта гораздо позднее. Сегодня известно, что средняя продолжительность жизни наркоманов после начала потребления наркотиков составляет 4-4,5 года, при этом большинство из них не задумываются о возможности заражения ВИЧ/СПИДом.

По оценке Управления ООН по наркотикам и преступности ${ }^{3}$, число жителей планеты в возрасте от 15 до 64 лет, употребляющих наркотики (в немедицинских целях), составляет примерно 200 млн человек, из которых 160,9 млн употребляют производные конопли, 26,2 млн амфетамины, 7,9 млн - экстази, 13,7 млн - кокаин, 10,6 млн - героин, 5,3 млн - другие опиаты.

В результате исследований, проведенных в отношении детей в возрасте 15-16 лет, выяснилось, что в 2006 году произошло увеличение количества детей, употребляющих кокаин в школах и распространяющих наркотики на улицах, особенно в странах Южной Америки, при этом 2,6 \% из них употребляют наркотики внутривенно. В США более 4,8 \% детей занимаются распространением наркотических веществ, в Европе - 2,4 \% и в Южной Америке - 2,35 \%. Эти показатели вызывают тревогу за будущее наций и человечества в целом ${ }^{4}$.

Борьба с незаконным употреблением наркотиков и их распространением была начата отдельными государствами путем принятия запретительных и ограничительных законодательных мер. Так, Турция еще в XVI веке запретила потребление опиума и гашиша. Индия и Китай

2 См.: Основы борьбы с организованной преступностью. М., 1996. С. 29-30.

3 Управление по наркотикам и преступности ООН (ЮНОДК) создано с целью укрепления международного сотрудничества в области противодействия злоупотреблению наркотиками и их незаконному обороту, а также в борьбе с преступностью.

4 См.: UNODC, 2006 World Drug Report 2007. P. 98-99. 
в XVIII веке ввели запрет на продажу опиума и опиокурение. В конце XIX века и начале XX века и другие государства (Франция, некоторые штаты США) приняли законы о наркотических веществах 5 . Однако в борьбе с растущей и распространяющейся наркоманией эти отдельные национальные меры были явно недостаточны. Возникла потребность в международном сотрудничестве. Первым международным органом по контролю за распространением наркотических средств стала созванная 13 государствами (в том числе Россией) и заседавшая с 5 по 26 февраля 1909 года Шанхайская опиумная комиссия, принявшая 9 резолюций, запрещающих экспорт опиума и устанавливающих контроль за производством морфина и других производных опиума ${ }^{6}$.

Первым международным договором в области борьбы с распространением наркотиков стала Международная конвенция по опиуму, подписанная в Гааге 23 января 1912 года. Далее были приняты: Женевское соглашение относительно производства опиума для курения, внутренней торговли и его использования от 11 февраля 1925 года; Международная конвенция по опиуму от 19 февраля 1925 года; Женевская конвенция об ограничении производства и о регламентации распределения наркотических средств от 13 июля 1931 года; Бангкокское соглашение об установлении контроля над курением опиума на Дальнем Востоке от 27 ноября 1931 года; Женевская конвенция по борьбе с незаконным оборотом вредных лекарственных веществ от 26 июня 1936 года, а также три Протокола: от 11 декабря 1946 года, от 19 ноября 1948 года и от 23 июня 1953 года 7

Указанные соглашения устанавливали определенную систему контроля за производством наркотических средств и торговлей ими ${ }^{8}$. Следует отметить, что в перечисленных договорах вопрос о наркомании среди детей особо не выделялся. Тем не менее уже в Женевском соглашении от 11 февраля 1925 года употребление опиума несовершеннолетними относилось к преступным деяниям; в Бангкокском соглашении от 27 ноября 1931 года к таким деяниям отнесли курение опиума лицами моложе 21 года и вовлечение несовершеннолетних в употребление опиума9.

\footnotetext{
5 См.: Анисимов Л.Н. Наркотики: правовой режим. М., 1977. С. 8-9.

6 См.: Галенская Л.Н. Международная борьба с преступностью. М., 1972. С. 63.

7 См.: Международное право и борьба с преступностью: Сб. документов. C. 314-315.

8 См.: Анисимов Л.Н. Указ. соч. С. 8-26.

9 См.: Галенская Л.Н. Указ.соч. С. 69.
} 
Принятая 30 марта 1961 года Единая конвенция о наркотических средствах заменила собой в отношениях между ее участниками все ранее принятые договоры, за исключением Конвенции от 26 июня 1936 года ${ }^{10}$. Она установила меры контроля в отношении готовых наркотиков и производства сырьевых продуктов (опийного мака, необработанного опиума, листьев коки и каннабиса). К основным задачам Конвенции относятся: ограничение культивирования, производства, изготовления и использования наркотических средств количеством, необходимым для медицинских и научных целей; предотвращение незаконного культивирования, производства, изготовления и использования наркотических средств и их незаконного оборота.

Страны, подписавшие Конвенцию, взяли на себя обязательство ежегодно представлять Генеральному секретарю ООН доклады о применении Конвенции на их территориях и тексты всех законов и нормативных актов, касающихся наркотических веществ, а также сообщать названия и адреса организаций, выдающих разрешения на вывоз или свидетельства на ввоз наркотиков, и статистические данные по наркотическим веществам.

На основании указанной Конвенции учрежден Международный комитет по контролю над наркотиками и расширены функции Комиссии по наркотическим средствам Экономического и Социального Совета ООН.

Конвенция установила правила международной торговли наркотическими средствами, определила, какие деяния, связанные с наркотиками, считаются наказуемыми. В список включены умышленное культивирование и производство, изготовление, извлечение, приготовление, хранение, предложение, предложение с коммерческими целями, распределение, покупка, продажа, доставка на каких бы то ни было условиях, маклерство, отправка, переотправка транзитом, перевоз, ввоз и вывоз наркотических средств. Эти действия, согласно Конвенции, могут наказываться лишением свободы.

Между тем в Конвенции ничего не говорится о мерах контроля над детской наркоманией. Участники Конвенции лишь берут на себя обязательство принимать меры по предотвращению злоупотребления

10 Единая конвенция вступила в силу 13 декабря 1964 года. С поправками, внесенными Протоколом от 25 марта 1972 года, она вступила в силу 8 августа 1975 года. Ее участниками по состоянию на 2006 год являются 180 государств. Текст Конвенции см.: Международное право и борьба с преступностью: Сб. документов. С. 276-331. 
наркотиками, раннему выявлению и лечению наркоманов, их социальной реабилитации, что, конечно, относится и к несовершеннолетним.

Принятая 21 февраля 1971 года в Вене Конвенция о психотропных веществах установила меры контроля за психотропными веществами, вызывающими при немедицинском потреблении последствия, сходные с последствиями при употреблении наркотиков ${ }^{11}$. Эти меры мало чем отличаются от мер по контролю за наркотиками, определенных Конвенцией 1961 года.

Конвенция 1971 года также специально не затрагивает проблему употребления наркотиков детьми.

Подписание странами - участниками Конвенций от 1961 года и 1971 года не препятствовало росту незаконного производства, спроса и оборота наркотических средств и психотропных веществ, их распространению в различных социальных группах и особенно среди детей. Это обстоятельство потребовало дальнейшего международного сотрудничества.

20 декабря 1988 года в Вене была принята Конвенция о борьбе против незаконного оборота наркотических средств и психотропных веществ ${ }^{12}$, в которой расширен список правонарушений, связанных с наркотическими средствами и психотропными веществами.

Следует обратить внимание, что Конвенция разработана и направлена в числе прочего и на защиту ребенка, о чем указано в ее преамбуле: «Дети во многих районах мира используются в качестве потребителей незаконных наркотических средств и психотропных веществ и эксплуатируются при их незаконном производстве и обороте, что представляет собой огромную опасность».

Нововведением стало то, что странам, подписавшим эту Конвенцию, предлагалось изменить законодательство таким образом, чтобы суды, рассматривающие правонарушения, связанные с наркотическими средствами и психотропными веществами, могли учитывать как отягчающие обстоятельства групповой характер преступления, участие обвиняемого в других преступлениях или в деятельности

11 Конвенция вступила в силу 16 августа 1976 года. По состоянию на 2006 год ее участниками являются 179 государств. Текст Конвенции см.: Международное право и борьба с преступностью: Сб. документов. С. 332-373.

12 Конвенция вступила в силу 11 ноября 1990 года. По состоянию на 2006 год ее участниками являются 180 государств. Текст Конвенции см.: Международное право и борьба с преступностью: С. 375-415. 
международной преступной группировки, применение насилия или оружия. Особенно важное значение имело включение в перечень правонарушений с отягчающими обстоятельствами «вовлечение или использование несовершеннолетних» (ст. 3, п. 5, f). К обстоятельствам, отягчающим правонарушение, было отнесено также совершение правонарушения «в учебном заведении или общественном учреждении, или непосредственной близости от них, или в других местах, которые используются школьниками и студентами для проведения учебных, спортивных и общественных мероприятий» (ст. 3, п. 5).

В целях усиления эффективности борьбы с наркоманией, включая детскую, вышеуказанные международные договоры исходят из того, что международный контроль над наркотиками должен сочетаться с соответствующим контролем на национальном уровне. Рассмотрим разрешение данной проблемы на примере России, для которой борьба с наркоманией имеет важное значение.

Российская Федерация наряду с Казахстаном, по данным Управления ООН по наркотикам и преступности, относится к самым большим территориям, где растет каннабис ${ }^{13}$. Стоимость наркотиков в России постоянно падает, количество наркоманов возрастает, в том числе среди детей. Происходит увеличение процентной доли дорогих и сильных наркотиков, таких как героин, кокаин и опиум. Так, по утверждению экспертов ООН из Совета по контролю за распространением наркотиков, более 4 млн россиян страдают зависимостью от героина ${ }^{14}$.

Наркотики достаточно легко входят в жизнь ребенка, и это можно объяснить такими причинами, как неосведомленность о последствиях применения наркотиков, низкий уровень правовой культуры населения, отсутствие доступных детских и молодежных организаций, потеря жизненных ценностей, недостаток внимания со стороны родителей, сложная социально-экономическая ситуация в стране.

Так по утверждению экспертов ООН из Совета по контролю за распространением наркотиков, более 4 млн россиян страдают зависимостью от героина 15 .

В качестве наркотиков в России широкое распространение получили маковая соломка, опий-сырец и опийный раствор, марихуана,

${ }^{13}$ Cм.: UNODC, 2006 World Drug Report 2007.

14 CM.: www.data.rbc.ru

${ }^{15}$ CM.: www.data.rbc.ru 
эфедрин, гашиш, героин, кокаин, «экстази» (метилендиоксиметиламфетамин). Вместе с тем особую опасность создает появление новых синтетических наркотиков, в том числе и производимых собственно в России. Серьезной проблемой России является то, что в стране в настоящее время существуют большие сложности с системой эффективного контроля на химических и фармацевтических предприятиях, использующих наркотики и их составляющие. Вызывает тревогу и то обстоятельство, что данные предприятия, попадая в частные руки, стремятся к получению коммерческой прибыли. В результате на российский рынок во все возрастающем объеме выбрасываются новые виды наркотиков и психотропных средств, в том числе мощного разрушающего действия.

Российская Федерация как правопреемник СССР является участницей Единой конвенции 1961 года с поправками от 1972 года - с 3 июля 1996 года; Конвенции о психотропных веществах 1971 года - с 1 февраля 1979 года; Конвенции о борьбе против незаконного оборота наркотических средств и психотропных веществ 1988 года - с 17 апреля 1991 года.

Согласно Федеральному закону Российской Федерации «О наркотических и психотропных веществах» от 8 января 1998 года № 3-Ф3, наркотические средства - это вещества синтетического или естественного происхождения, препараты, растения, включенные в Перечень наркотических средств, психотропных веществ и их прекурсоров, подлежащих контролю в Российской Федерации в соответствии с ее законодательством и Единой конвенцией о наркотических средствах 1961 года.

Психотропные вещества - это вещества синтетического или естественного происхождения, препараты, природные материалы, включенные в Перечень наркотических средств, психотропных веществ и их прекурсоров, подлежащих контролю в Российской Федерации в соответствии с международными договорами Российской Федерации, в том числе Конвенцией о психотропных веществах 1971 года.

Уголовный кодекс Российской Федерации от 13 июня 1996 года предусмотрел уголовную ответственность за ряд преступлений, связанных с наркоманией, и среди них - вовлечение несовершеннолетнего в систематическое употребление одурманивающих веществ (ст. 151). Подобное законодательство имеется и в других странах (например, в Японии, Франции, Финляндии, Швеции, Швейцарии, ОАЭ, Австралии). 
Значительную помощь государствам в борьбе с детской наркоманией оказывает Детский фонд Организации Объединенных Наций (ЮНИСЕФ) - единственное учреждение ООН, уполномоченное заниматься защитой прав детей. Фонд основан Генеральной Ассамблеей ООН в 1946 году для оказания помощи детям в преодолении возникающих перед ними препятствий, таких как бедность, насилие, болезни, дискриминация.

Целью ЮНИСЕФ является разработка механизмов защиты прав детей на получение медицинской помощи, образования и социального развития ${ }^{16}$. К основным программным направлениям Детского фонда ООН в соответствии с его мандатом относятся: «Развитие в раннем детстве», «Здоровье и развитие молодежи», «Дети, нуждающиеся в особой защите», «Общество на защите прав детей».

ЮНИСЕФ действует в интересах детей в зависимости от их потребностей и без какой бы то ни было дискриминации. Через 126 офисов, расположенных по всему миру, Фонд сотрудничает с 196 странами в целях помощи детям, нуждающимся в их защите, но большей поддержкой пользуются наименее развитые страны, и особое внимание уделяется предотвращению болезней и смертности детей до 5 лет. При этом ЮНИСЕФ стремится обеспечить выполнение в полной мере Конвенции о правах ребенка 1989 года и двух Факультативных протоколов к ней от 2000 года, в которых закреплены универсальные этические принципы и международно-правовые стандарты, касающиеся защиты и повышения благосостояния детей 17.

Основные направления деятельности Фонда соответствуют целям и задачам, изложенным в итоговом документе специальной сессии Генеральной Ассамблеи ООН по положению детей от 8-10 мая 2002 года «Мир, пригодный для жизни детей»18, в котором определены такие главные приоритеты на следующее десятилетие, как содействие здоровому образу жизни; содействие обеспечению качественного образования для всех; защита детей от жестокого обращения, эксплуатации и насилия; борьба с наркоманией, ВИЧ/СПИДом ${ }^{19}$.

\footnotetext{
16 См.: Резолюция Генеральной Ассамблеи ООН 57(I) от 11 декабря 1946 года.

17 См. подробнее: Мусина Н.М. Детский фонд ООН (ЮНИСЕФ) // Московский журнал международного права № 2 (62). 2006. С. 57-71.

18 См.: Резолюция Генеральной Ассамблеи ООН S-27/2 от 11 октября 2002 года. http:// unbisnet.un.org.

19 См.: www.un.org.
} 
Генеральная Ассамблея ООН на 47-й сессии приняла резолюцию от 26 апреля 1993 года, в которой первоочередное внимание уделено мерам, направленным на решение проблем, связанных с вовлечением детей в потребление, производство и незаконное распространение наркотических средств и психотропных веществ ${ }^{20}$.

Для обеспечения здорового образа жизни не только взрослых, но и детей необходима эффективная борьба с наркоманией. Важность этой задачи определяется тем обстоятельством, что инъекционное употребление наркотиков связано в значительной степени с заражением и распространением ВИЧ/СПИДа. Оно является одним из основных способов передачи ВИЧ-инфекции во многих странах Азии, Европы, Латинской Америки и Северной Америки. К примеру, в некоторых странах, включая Бахрейн, Грузию, Испанию, Италию, Казахстан, Аргентину, Иран, Португалию и Югославию, более половины всех случаев ВИЧ/СПИДа являются следствием употребления наркотиков через инъекции.

Деятельность ЮНИСЕФ по борьбе с распространением детской наркомании входит в два его основных программных направления «Здоровье и развитие молодежи» и «Дети, нуждающиеся в особой защите». В рамках данных направлений Фонд участвует в программах, разрабатываемых совместно с партнерами. Так, ЮНИСЕФ совместно с другими учреждениями ООН участвует в Объединенной программе ООН по ВИЧ/СПИД (ЮНЭЙДС) 21 с момента ее создания (1996 год) и учитывает при этом в своей деятельности приоритетные его направления, включающие защиту женщин, молодежи, уязвимых слоев населения, передачу инфекции от матери ребенку, стандарты лечения, разработку вакцин, разработку специальных программ для наиболее пострадавших регионов Африки.

По данным ЮНЭЙДС, только в 2007 году количество ВИЧ-инфицированных, в том числе и в результате инъекционного употребления наркотиков, по всему миру превысило 40 млн человек, и более чем 2 млн из них - дети ${ }^{22}$. Более 600 тыс. детей ежегодно заражаются ВИЧ-инфекцией, в основном путем передачи вируса от матери к ре-

20 См.: Резолюция ГА ООН А/RES/47/102 от 26 апреля 1993 года.

21 В ЮНЭЙДС участвуют Детский фонд ООН, Мировая продовольственная программа, Программа развития ООН, Фонд ООН в области народонаселения, Управление $\mathrm{OOH}$ по наркотикам и преступности, Международная организация труда, Всемирная организация здравоохранения, Всемирный банк.

${ }^{22}$ См.: www.unaids.org. 
бенку, большинство детей становятся наркозависимыми от своих родителей, в связи с чем обеспечение доступа к недорогой диагностике и лечению при наркомании и ВИЧ является неотложным глобальным приоритетом в сфере здравоохранения 23 .

Основную часть работы ЮНЭЙДС, в том числе ЮНИСЕФ, проводят в странах, предпринимающих усилия по противодействию эпидемии ВИЧ. Объединенная программа помогает координировать деятельность организаций системы ООН по борьбе с наркоманией, ВИЧ/СПИДом. Страновые координаторы Фонда оказывают стратегическую поддержку тематическим группам ОOH, правительствам и другим национальным партнерам.

В рамках ежегодно проводимой Всемирной кампании по СПИДу особое внимание уделяется распространению информации о способах передачи ВИЧ, в том числе через употребление наркотиков.

На состоявшемся в сентябре 2005 года Саммите тысячелетия лидеры стран мира подписали Декларацию тысячелетия, в которой взяли на себя обязательства предпринимать всевозможные действия для прекращения к 2015 году распространения ВИЧ/СПИДа и наркомании.

ЮНИСЕФ как межправительственная организация, деятельность которой направлена на защиту детей на международном уровне, участвует в разработке большинства программ, проектов, мероприятий, благотворительных акций, направленных на борьбу с распространением наркотиков, ВИЧ-инфекции среди детей. Такие мероприятия разрабатываются в зависимости от потребностей стран и государств.

При разработке стратегических программ по борьбе с наркоманией среди детей ЮНИСЕФ руководствуется статьей 33 Конвенции о правах ребенка 1989 года, в которой указано: «Государства-участники принимают все необходимые меры, включая законодательные, административные и социальные меры, а также меры в области образования, с тем чтобы защитить детей от незаконного употребления наркотических средств и психотропных веществ как они определены в соответствующих международных договорах, и не допустить использования детей в противозаконном производстве таких веществ и торговле ими ${ }^{24} \gg$. Указанной нормой международного права должны

23 Cм.: Source: 2006 Report on the global AIDS epidemic, UNAIDS. P. 183.

24 Действующее международное право. В 3 томах. Составители Ю.М. Колосов и Э.С. Кривчикова. Т. 2. М.: Издательство Московского независимого института международного права, 1997. С. 60. 
руководствоваться и страны, взявшие на себя такое обязательство при ее подписании.

Приоритетные сферы деятельности ЮНИСЕФ в борьбе против распространения наркотиков включают проведение профилактики среди молодежи, информирование детей о последствиях применения наркотических веществ, обеспечение ухода и поддержки для уязвимых детей и сирот, чьи родители умерли в результате употребления наркотиков.

Фонд, помимо того что является участником ЮНЭЙДС, также участвует в Программе ООН по международному контролю за наркотиками (ЮНДКП 25 . При этом ЮНИСЕФ осуществляет содействие в работе по снижению уровня злоупотребления наркотиками, особенно среди молодежи и уязвимых групп населения; налаживает на местном, национальном и международном уровнях сотрудничество по вопросам борьбы с наркотиками; обеспечивает информацию, анализ и услуги специалистов по связанным с наркотиками вопросам. Подкомиссия ЮНДКП ежегодно заседает для выработки стратегий координации работы по контролю над наркотиками по всей системе ООН и отвечает за составление плана действий, включающего планы и деятельность всех агентств ООН на основе секторальных и межсекторальных повесток, отражающих региональные и национальные проблемы и деятельность. При этом каждый член организации является своеобразным отображением того, что делается на национальном уровне.

ЮНИСЕФ, предпринимая попытки объединить государства в целях сотрудничества против наркоэпидемии, предложил свой проект в борьбе с наркотиками: «Программу улучшения и охраны здоровья молодых людей». Фонд признает, что проблема наркомании и ее последствий в виде ВИЧ/СПИДа неразрывно связана с рядом проблем, с которыми сталкиваются дети и подростки, включая злоупотребление алкоголем и наркотиками, заболевания, передаваемые половым путем, и социальную изоляцию (дети улиц; дети, находящиеся в специализированных учреждениях закрытого типа). По этой причине программы профилактики ВИЧ/СПИДа и заболеваний, передаваемых половым путем, злоупотребления наркотиками и программы их лечения являются неотъемлемой частью Программы улучшения и охраны здоровья детей и подростков в Центральной и Восточной Европе, странах - членах Содружества Независимых Государств (СНГ) и государствах Балтии.

25 См.: Резолюция ГА ООН № 45/179 от 29 декабря 1990 года. 
Программа осуществляется в сотрудничестве с правительствами, неправительственными организациями и спонсорами ЮНЭЙДС и способствует разработке национальных ответных мер, которые:

1) обеспечивают детей и подростков соответствующей информацией и помогают сформировать навыки, которые позволяют им выбрать здоровый образ жизни и тем самым защитить себя от наркотиков, ВИЧ/СПИДа, инфекций, передаваемых половым путем и путем злоупотребления наркотиками;

2) создают безопасную и стимулирующую детей и подростков среду, свободную от насилия, жестокого обращения и эксплуатации;

3) обеспечивают конфиденциальные и доступные услуги, которые удовлетворяют потребности подрастающего поколения;

4) помогают детям и подросткам определить свои обязанности и сформировать навыки, которые позволят им выполнять эти обязанности;

5) помогают создать механизмы, гарантирующие соблюдение прав молодых людей, в том числе дающие им возможность играть значимую роль в процессах принятия затрагивающих их решений;

6) ориентируются на потребности не только мальчиков, но и девочек, включая тех из них, которые находятся в специализированных учреждениях или вне школьной системы.

Фонд в рамках вышеуказанных программ проводит обучение работников здравоохранения и преподавателей, работающих непосредственно с детьми, максимальное внимание уделяет психологическому, познавательному и эмоциональному развитию детей. Через систему образования ЮНИСЕФ распространяет знания, касающиеся наркотических веществ и психотропных средств, ВИЧ/СПИДа, сексуальных отношений и беременности.

Государственные медицинские учреждения, сотрудничающие с ЮНИСЕФ и получившие статус «Клиник, дружественных молодежи», оказывают медицинские услуги, дают консультации и оказывают социальную поддержку молодым людям. Эти учреждения работают в соответствии с принципами доброжелательности, доступности и конфиденциальности. Начиная с 1999 года при поддержке ЮНИСЕФ было открыто 37 «клиник, дружественных молодёжи», более 300 специалистов было обучено работе на основе дружественного отношения к молодёжи, около 500 тыс. молодых людей получили медицинскую помощь, консультации по последствиям употребления 
наркотических веществ и психотропных средств, репродуктивному здоровью, половому поведению и другим деликатным вопросам.

В Российской Федерации и на Украине несколько молодежных клиник, созданных при поддержке ЮНИСЕФ, занимаются санитарным просвещением детей и подростков, предоставляют им медицинские услуги и проводят с ними образовательную беседу. В Калининграде и Санкт-Петербурге проводятся консультации для подростков относительно предупреждения злоупотребления наркотиками, организуются просветительские программы для лиц, употребляющих наркотики, а также для членов их семей и учителей, в рамках которых преподавание осуществляют в том числе и бывшие наркоманы ${ }^{26}$.

Быстрый экономический рост, сопровождаемый урбанизацией и миграцией, привел к увеличению числа детей, нуждающихся в такой специальной защите. По словам медиков, до сих пор нет механизма лечения наркозависимых детей, отсутствуют специалисты по социальной работе. При этом следует заметить, что дети, употребляющие наркотики, нуждаются не только в медикаментозной, но и в психикокоррекционной профилактике 27.

Решение проблем распространения и употребления наркотических веществ требует совместных усилий как на национальном, так и на международном уровне; привлечения более широких слоев общества к планированию и осуществлению соответствующих мер, надлежащей оценке потребностей; обеспечения программ подготовки для приобретения новых навыков; расширения доступа к широкому кругу услуг, основанных на реальных случаях практики, а также создания систем мониторинга.

Наработанный опыт позволил ЮНИСЕФ создать эффективную модель организации и проведения кампаний, основанную на международном опыте и учитывающую местную специфику. Неотъемлемой частью каждой кампании являются предварительные социологические исследования среди представителей каждой отдельной страны, а также мониторинг и оценка результатов.

В настоящий момент для совершенствования механизмов борьбы с распространением и употреблением наркотиков детьми необходимо внедрение таких мероприятий, как:

${ }^{26}$ См.: D.S/ Mugrditchian, "HIV/AIDS epidemic in the Baltic Sea region, an overview of the international response".

27 См.: Научный журнал «Управление здравоохранением». 1/2002 (№ 5). 
- во-первых, информирование ребенка о последствиях наркомании;

- во-вторых, с целью понимания детьми серьезности проблемы наркоэпидемии привлечение их к социальной помощи в борьбе против наркомании в качестве наблюдателей;

- в третьих, оформление впечатлений детей по данной проблеме, что позволит найти новые пути решений борьбы с наркоманией, ВИЧ/ СПИДом с меньшими экономическими затратами;

- в-четвертых, своевременное оказание социально-психологической поддержки, что является немаловажным фактором для развития ребенка в будущем.

Эффективная политика в интересах детей в каждой стране должна основываться на точном знании и понимании настоящего положения детей, их потребностей и способов наилучшего удовлетворения этих потребностей. Защита детей от наркомании - это одна из международных целей защиты прав человека и увеличение экономического потенциала каждой страны в целом. 


\section{Combating Drug Addiction among Children by the UNICEF \\ (Summary)}

\section{Nailya M. Musina*}

The article focuses on drugs and on the ways how to combat this problem because drugs influence many spheres of our lives and one of the most significant goals of the human kind is to find a remedy to drug addiction and elaborate ways of fighting circulation of drugs. One of the crucial problems here is the inclusion of children into the sphere of interests of drug dealers who drag them into this business for the sake of extra gains. We witness the horror and the complexity of the problem and clearly see the necessity of dealing with it as it touches upon every one of us and especially our children.

Further the article offers the list of most common drugs and demonstrates effects they have on people. Afterwards the author shifts to the legal ways of fighting different aspects of drug addiction and circulation of drugs and enumerates several conventions on this subject.

In its latter part the author pays attention to the ways of combating drug-addiction in the framework of the UN and particularly UNICEF. The Children's Fund of the United Nations Organization together with the international and regional organizations, official bodies, educational centers implements different programs in the sphere of prevention, assistance and research in the field of fighting drugs. The UNICEF tries to unite the states to cooperate against "drug epidemic" by developing different programs, projects, and charitable actions. The complex strategy directed towards the reduction of drug abuse and spread of a HIV-infection, is of vital importance, as it will make the struggle against drugs more effective.

\footnotetext{
* Nailya M. Musina - post-graduate student of the Chair of International law, MGIMO-University, MFA Russia.
} 